\title{
Ten-year survival and patient-reported outcomes of a medial unicompartmental knee arthroplasty incorporating an all- polyethylene tibial component
}

\author{
Chloe E. H. Scott ${ }^{1} \cdot$ Frazer A. Wade $^{1} \cdot$ Deborah MacDonald $^{1} \cdot$ Richard W. Nutton $^{1}$
}

Received: 23 November 2017 / Published online: 23 February 2018

(c) The Author(s) 2018. This article is an open access publication

\begin{abstract}
Introduction Biomechanical studies have suggested that proximal tibial strain is elevated in UKAs incorporating all-polyethylene tibial components with concern that this leads to premature failure. This study reports minimum 10-year outcomes for a UKA incorporating an all-polyethylene tibial component to determine whether these concerns were realised.

Materials and methods 109 fixed bearing UKAs (97 patients, mean age 68 (range 48-87), 54/97 (56\%) female) with allpolyethylene tibial components were followed up for $\geq 10$ years with Oxford Knee Scores, Forgotten Joint Scores and Kaplan-Meier analysis. 106/109 implants were $7 \mathrm{~mm}, 3$ were $9.5 \mathrm{~mm}$.

Results Ten-year survival was 85.5\% (78.6-92.4 95\% CI) with the end-point failure for any reason. Unexplained pain was the commonest mode of failure (6/17) followed by lateral compartment osteoarthritis (5/17) and tibial subsidence/loosening (4/17). Revision rate was highest at 2-5 years due to revisions for unexplained pain. Ten-year survival was worse in patients $<65$ years old $(p=0.035)$, in those with BMI $>30(p=0.017)$ and in those with postoperative increases in medial tibial sclerosis $(p<0.001$ log-rank). Implant malalignment was not significantly associated with failure. Radioisotope bone scans in 16 patients all remained "hot" at mean 6.1 years (range 2.1-11.5). Relative risk of failure in patients $<65$ years was $2.9(1.2-7.095 \% \mathrm{CI})$ and when BMI > 30 was 2.9 (1.2-6.9 95\% CI). In those with intact UKAs at 10 years, mean Oxford Knee Score was $34.8 \pm 10.7$, Forgotten Joint Score was $37.9 \pm 26.7$ and $96 \%$ were satisfied with their knee.

Conclusion The high rate of early failure between 2 and 5 years in this all-polyethylene tibial component UKA did not persist in the long term. Though medial proximal tibial metabolic changes appear to persist they are not necessarily symptomatic. $\mathrm{BMI}>30$ and age $<65$ years were significant risk factors for revision.
\end{abstract}

Keywords Unicompartmental knee arthroplasty $\cdot$ Long-term survival $\cdot$ All-polyethylene tibia

\section{Introduction}

Joint registries consistently show higher revision rates for unicompartmental knee arthroplasties (UKAs) compared to total knee arthroplasties (TKAs) [1,2]. Registries do not distinguish between all-polyethylene and metal-backed tibial components in fixed bearing UKAs. Some cohort studies have reported high early failure rates in all-polyethylene UKAs [3-5], but this is not consistently reported and some

Chloe E. H. Scott

chloe.scott@nhslothian.scot.nhs.uk

1 Department of Orthopaedics, Royal Infirmary of Edinburgh, 51 Little France Crescent, Old Dalkeith Road, Edinburgh EH16 4SA, UK all-polyethylene designs perform well into the long term [6-9]. After component loosening, unexplained pain is the leading mode of failure of UKAs in the United Kingdom [10]. Elevated proximal tibial strain with repetitive microfracture and remodelling may contribute to this pain [11]. Biomechanical studies have demonstrated greater microdamage in composite bone models implanted with all-polyethylene UKA tibial components compared to metal-backed implants [12] and finite element analysis has shown elevated strain to be dependent upon all-polyethylene implant thickness [13]. Elevated proximal tibial strain under all-polyethylene UKA tibial components may cause changes in local cancellous bone architecture and predispose to early failure by tibial subsidence, aseptic loosening or ongoing pain. It is unclear whether early failures in UKAs with all-polyethylene 
tibial components due to unexplained pain and tibial failure continue at mid-term and long-term follow-up.

The aim of this study was to report the 10-year survival and patient-reported outcomes of a medial fixed bearing UKA incorporating an all-polyethylene component to determine

1. Whether elevated proximal tibial strain and pain resolve with time.

2. Whether an elevated short-term revision rate for "unexplained" pain persists in the longer term.

\section{Materials and methods}

Ethical approval was obtained for this retrospective cohort study. From 2003 to 2007, 109 fixed bearing UKAs with all-polyethylene tibial components (Preservation, DePuy, Johnson \& Johnson, Raynham, Massachusetts, USA) were performed in 97 consecutive patients at our institution. Mean age was 68 (median 68, range 48-87) and 54/97 (56\%) patients were female. Sixty-two procedures were left sided, 106/109 (97\%) utilised a 7-mm tibial component and 3/109 (3\%) a 9.5-mm tibial component. Indications for surgery were isolated medial compartment degeneration with an intact ACL, fixed flexion deformity of $<10^{\circ}$, a correctible varus deformity of $<15^{\circ}$, subluxation $<1 \mathrm{~cm}$ and knee flexion beyond $90^{\circ}$. Operations were performed by two experienced consultant knee surgeons.

Medical and operation notes were reviewed for all patients. Data recorded included age, sex, weight, body mass index (BMI), indication for surgery and implants used.

Prior to surgery, all patients completed a Short-Form (SF-12) [14] Health Questionnaire (physical and mental components) and Oxford Knee Score (OKS) [15]. The OKS is a validated knee specific outcome measure of 12 questions with five possible answers giving a score from 0 to 48 . Higher scores represent better function. Postoperative questionnaires including SF-12 and OKS scores were sent at 12 months. In April 2013 and again in April 2017 a similar questionnaire was sent to patients with the addition of patient satisfaction measurements, the Forgotten Joint Score (FJS) and knee specific pain questions. Patients were asked, 'How satisfied are you with your operated knee?' with options 'very satisfied', 'satisfied', 'unsure', or 'dissatisfied' [16]. The FJS is a validated hip/knee specific outcome measure which assesses how aware the patient is of their arthroplasty when undertaking 12 activities [17]. It is scored from 0 to 100 with 100 representing a high degree of "forgetting" their arthroplasty. Patients were asked to indicate the pain level from their knee with a visual analogue pain scale (VAS) from no pain (0) to the worst pain imaginable (100). Patients were asked if they had undergone revision or reoperation of their UKA for any reason with tick-box options. This data was correlated with the notes.

Radiographic analysis included measuring alignment [18] on preoperative and postoperative short-leg weight-bearing radiographs and examining later radiographs for evidence of implant loosening or radiographic failure. An additional measure of medial proximal tibial sclerosis (the greyscale ratio-GSR [19]) was measured using digital radiodensitometry on preoperative and follow-up radiographs at 1,2 and 5 years. Details of this method can be found in Scott et al. [19]. This is a relative measure of sclerosis comparing the medial proximal tibial quadrant to that of the rest of the proximal tibia with a GSR $>1.0$ representing relative medial sclerosis. The femorotibial angle (FTA) was measured both pre- and postoperatively in addition to postoperative coronal and sagittal implant alignment [18]. Patient imaging histories were examined to identify radioisotope bone scans. Where performed the indication for radioisotope bone scanning was recorded and the results examined.

\section{Statistical analysis}

Statistical analysis was performed using Statistical Package for Social Sciences version 21.0 (SPSS Inc., Chicago, Illinois). In patients who had undergone bilateral UKA, PROMs pertaining to the second knee were excluded to avoid bias. Univariate analysis was performed using parametric (Student's $T$ test: paired and unpaired) and nonparametric (Mann-Whitney $U$ test) tests as appropriate to assess continuous variables for significant differences. Nominal categorical variables were assessed using a Chisquare or Fisher's exact test. Pearson's correlation was used to assess the relationship between linear variables. A $p$ value of $<0.05$ was considered statistically significant. Survival analysis was undertaken with life-tables and Kaplan-Meier analysis. The end points used were failure for any reason and revision to TKA.

\section{Results}

During the study period 109 fixed bearing UKAs with all-polyethylene tibial components were implanted in 97 patients (Fig. 1). Preoperative characteristics are given in Table 1 . Over the study period 28 patients with $32 / 109$ UKAs died (29\%) and a further 16/109 (15\%) were revised. Mean length of follow-up was 11.4 years (1.0 SD, 10.0-13.2) and no patients were lost to follow-up.

\section{Survival analysis}

The life table for all failures is given in Table 2. Over the study period, 17 UKAs failed and 16 were revised (Table 3 ). 


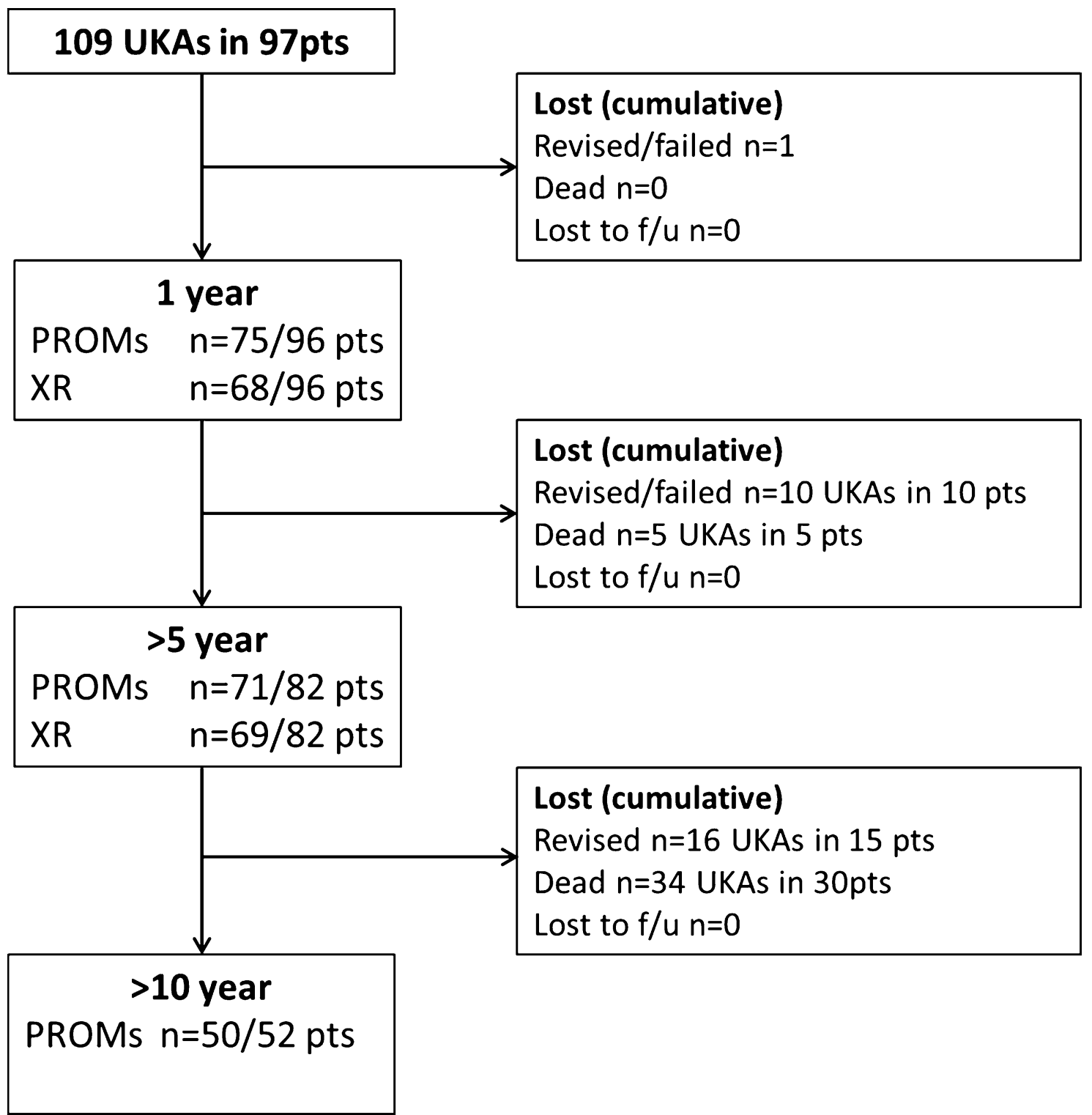

Fig. 1 Consort diagram of UKA cohort

One case of failure by tibial subsidence at 9 years has not been revised due to poor medical health. All failures incorporated a 7-mm tibial component. Revisions for unexplained pain were performed earlier (mean 3.5 years, range, 2.2-6.6) than revisions for other causes (mean 5.6 years, range, $0.2-10.7$ ), though this was not statistically significant ( $p=0.350$, Mann-Whitney $U$ test). Kaplan-Meier analysis demonstrated 10-year survival of $86.6 \%$ (80.1-93.1\% 95\% CI) with revision as an end point. Including the additional unrevised case of tibial subsidence gave 10-year survival of $85.5 \%$ (78.6-92.4 95\% CI) with failure for any reason as an end point (Fig. 2). Excluding revisions for unexplained pain, which could be considered as discretionary, gave a 10-year survival of $90.8 \%$ (85.1-96.5 95\% CI).
Characteristics of patients with intact and failed UKAs are given in Table 4 . With failure for any reason as an end point, 10-year survival was significantly inferior in patients under 65 years of age, patients with BMI $>30$ and in those whose GSR increased by greater than $10 \%$ in the first year (Table 5; Fig. 3). BMI was significantly higher in patients $<65$ years compared to those $\geq 65(30.9 \pm 5.4$ vs 27.6 $\pm 3.6, p=0.001$, unpaired $T$ test), and age was significantly younger in patients with $\mathrm{BMI}>30$ compared to those with $\mathrm{BMI}<30(62.8 \pm 6.7$ vs $70.1 \pm 8.7, p<0.001$, unpaired $T$ test). Figure 4 demonstrates the relationship between age, BMI and failures. Of 18 patients both $<65$ years old and with BMI $>30,8(44 \%)$ failed requiring revision $(p=0.001$, Chi-squared). 
Table 1 Preoperative patient characteristics

\begin{tabular}{llc}
\hline & Mean (SD), number [\%] & Range \\
\hline Age & $68(8.9)$ & $48-87$ \\
Female & $54 / 97[56]$ & \\
BMI & $28.8(4.6)$ & $20-42$ \\
Weight & $79.1(14.9)$ & $48-110$ \\
Femorotibial angle & $181.6(2.6)$ & $175-191$ \\
$\quad$ deg) & & \\
Indication & & \\
OA & $107 / 109[98]$ & \\
AVN & $2 / 109[2]$ & \\
PROMs & & $17-48$ \\
SF-12 & & $19-67$ \\
$\quad$ PCS & $31.2(7.1)$ & $8-34$ \\
$\quad$ MCS & $50.7(11.5)$ & \\
OKS & $20.2(5.9)$ & \\
\hline
\end{tabular}

Relative risk of failure in patients under 65 was 2.9 (1.2-7.0 95\% CI) times that of patients over 65 years. Relative risk of failure in patients with BMI $>30$ was 2.9 (1.2-6.9 95\% CI) times that of patients with $\mathrm{BMI} \leq 30$. Relative risk of failure in patients $<65$ with $\mathrm{BMI}>30$ was 3.64 (1.7-7.8 95\% CI). Ten of the 17 UKA failures displayed tibial-sided failure (tibial subsidence/loosening, fracture or unexplained pain). Ten-year survival functions for tibial-sided failure are shown in Table 6. Tibial survival was again significantly inferior in patients under 65 years of age, those with BMI $>30$ and in those with medial sclerosis with an increase in GSR of $>10 \%$.

Of six patients who were revised and had increases of $>10 \%$ in GSR, two had pain and 2 tibial subsidence as the mode of failure.

\section{PROMs}

Long-term PROMs were available for 67/92 (73\%) patients alive with intact UKAs at 5 years and 57/58 (98\%) patients alive with intact UKAs at 10 years. At 10 years, 96\% with intact UKAs were satisfied or very satisfied with their knee. This was significantly greater than those satisfied at 5 years (81.5\%, $p=0.007$, Chi-squared), despite a decline in OKS from 5 to 10 years. This may reflect revision of a further 6 UKAs between 5 and 10 years. The mean Forgotten Joint Score at 10 years was $37.9 \pm 26.7$ (range 0-80).

The decline in mean OKS from 5 to 10 years was not significant ( $p=0.388$ paired $T$ test, -1.5 to $3.895 \% \mathrm{CI}$ ) and the improvement in OKS from preoperative levels remained at 10 years ( $p<0.001$ paired $T$ test, -15.8 to $-8.195 \% \mathrm{CI}$ ). Following revision to TKA, patients revised for pain had significantly worse OKSs than patients revised for other reasons $(21.8 \pm 8.6$ vs $31.3 \pm 5.2, p=0.043$ unpaired $T$ test, $0.3-18.6$ $95 \% \mathrm{CI})$. VAS pain scores increased from a median of 7 (mean 20,0-99) at 5 years to 20 (mean 27, 0-85) at 10 years, though this was not significant ( $p=0.309$, Wilcoxon rank).

Age did not correlate significantly with OKS or with SF-12 physical component scores (PCS) or mental component scores (MCS) at any time point. There was no significant difference in OKS between patients older and younger than $65(32.9 \pm 11.4$ vs $32.7 \pm 10.3, p=0.923$ unpaired $T$ test, - 5.5 to $5.095 \% \mathrm{CI}$ ) or between those with BMIs greater than or less than $30(33.7 \pm 10.3$ vs $32.4 \pm 11.1, p=0.628$ unpaired $T$ test, -4.2 to $6.995 \% \mathrm{CI}$ ) at 10 years, or at any other timepoint.

\section{Radiographic outcomes}

Component alignments are detailed in Table 4. There were no significant differences in tibial or femoral alignment
Table 2 Life table for all failures

\begin{tabular}{llllllll}
\hline Interval & $N$ & Failures & Withdrawals & At risk & $\begin{array}{l}\text { Failure rate } \\
(\%)\end{array}$ & $\begin{array}{l}\text { Cumulative } \\
\text { survival }\end{array}$ & $95 \%$ CI \\
\hline $0-1$ & 109 & 1 & 0 & 109 & 1 & 99.1 & $97.3-100$ \\
$1-2$ & 108 & 0 & 1 & 107.5 & 0 & 99.1 & $97.3-100$ \\
$2-3$ & 107 & 5 & 0 & 107 & 5 & 94.5 & $90.2-98.8$ \\
$3-4$ & 102 & 3 & 2 & 101 & 3 & 91.6 & $86.4-96.8$ \\
$4-5$ & 97 & 1 & 2 & 96 & 1 & 90.7 & $85.2-96.2$ \\
$5-6$ & 94 & 0 & 2 & 93 & 0 & 90.7 & $85.2-96.2$ \\
$6-7$ & 92 & 1 & 3 & 90.5 & 1 & 89.7 & $83.9-95.5$ \\
$7-8$ & 88 & 1 & 2 & 87 & 1 & 88.7 & $82.6-94.8$ \\
$8-9$ & 85 & 2 & 1 & 84.5 & 2 & 86.6 & $80.0-93.2$ \\
$9-10$ & 82 & 1 & 10 & 77 & 1 & 85.4 & $78.6-92.2$ \\
$10-11$ & 71 & 2 & 17 & 62.5 & 3 & 82.7 & $75.0-90.3$ \\
$11-12$ & 52 & 0 & 27 & 38.5 & 0 & 82.7 & $75.0-90.3$ \\
$>12$ & 29 & 0 & 25 & 14.5 & 0 & 82.7 & $75.0-90.3$ \\
\hline
\end{tabular}


Table 3 Failed UKAs

\begin{tabular}{|c|c|c|c|c|c|}
\hline Sex & Age & BMI & Survival (years) & Mode of failure & Malalignment? \\
\hline M & 66 & 29 & 0.2 & Tibial subsidence & Varus tibia $6^{\circ}$ \\
\hline $\mathrm{F}$ & 71 & 30 & 2.2 & Aseptic loosening femur & Varus tibia $6^{\circ}$ \\
\hline $\mathrm{F}$ & 78 & 26 & 2.2 & Lateral OA & Flexed femur $22^{\circ}$ \\
\hline $\mathrm{F}$ & 55 & 34 & 2.25 & Pain & \\
\hline M & 61 & 32 & 2.4 & Pain & \\
\hline M & 61 & 31 & 2.6 & Periprosthetic fracture & \\
\hline M & 65 & 29 & 3.0 & Pain & Varus tibia $6^{\circ}$ \\
\hline $\mathrm{F}$ & 60 & 31 & 3.5 & Pain & \\
\hline M & 65 & 31 & 3.5 & Pain & \\
\hline $\mathrm{F}$ & 70 & 31 & 4.6 & Lateral OA & Varus femur $6^{\circ}$ \\
\hline M & 60 & 39 & 6.6 & Pain & \\
\hline $\mathrm{F}$ & 53 & 32 & 7.1 & Lateral OA & Reverse tibial slope $3^{\circ}$ \\
\hline$F^{a}$ & 62 & 37 & 8.1 & Aseptic loosening femur \& tibia & \\
\hline $\mathrm{F}$ & 61 & 21 & 8.4 & Lateral OA & Varus tibia $5^{\circ}$ \\
\hline $\mathrm{F}$ & 55 & 30 & 10.3 & Lateral OA & Varus tibia $8^{\circ}$ \\
\hline $\mathrm{F}^{\mathrm{a}}$ & 61 & 37 & 10.7 & Tibial subsidence & \\
\hline
\end{tabular}

${ }^{a}$ Denotes the same patient requiring revision of bilateral UKAs

Fig. 2 Kaplan-Meier survival analysis at 10 years with all failures as the end point

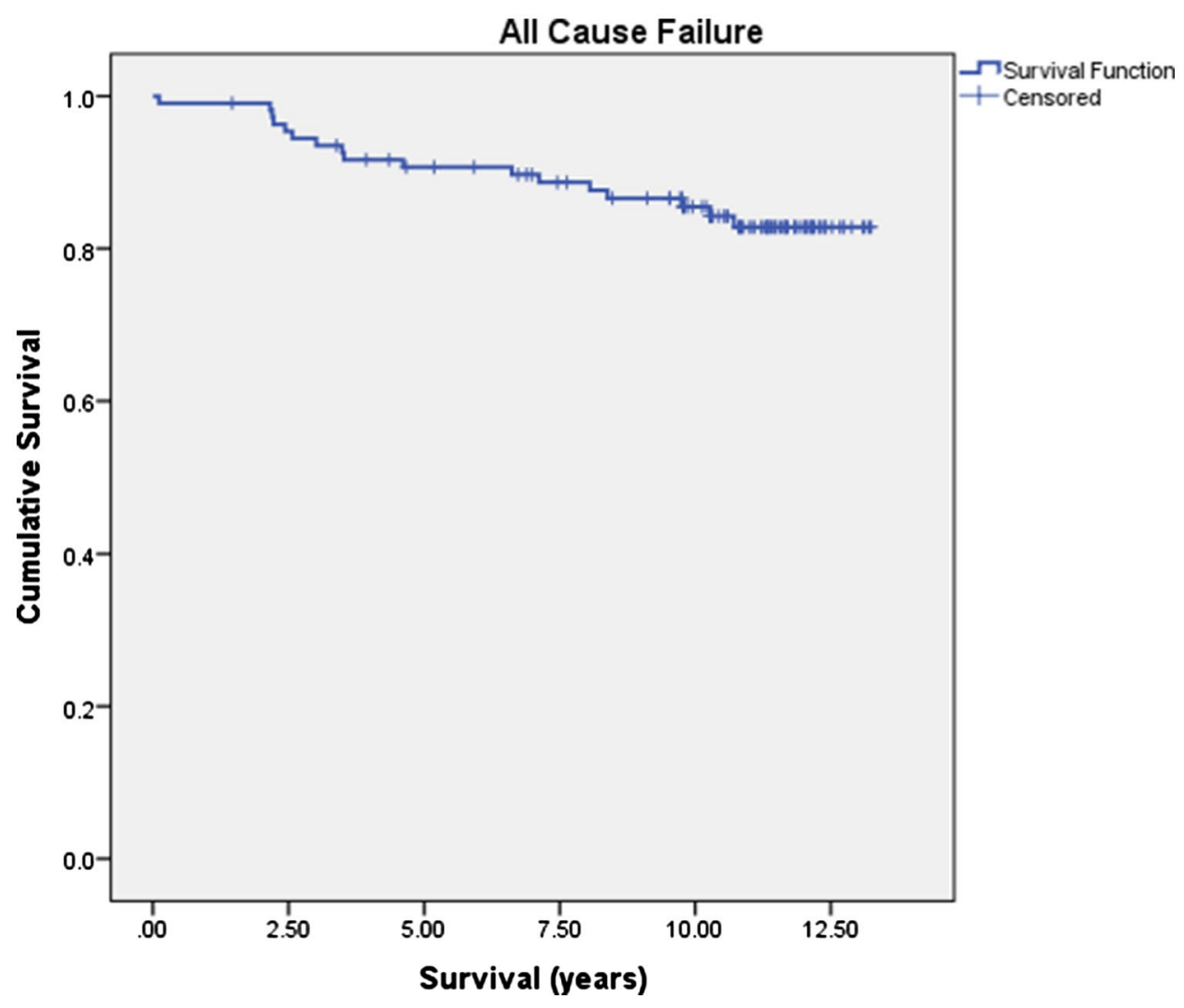

between UKAs which went on to fail for any reason (Table 4) or for tibial-sided failure. Over or underhang was not significantly associated with all-cause failure $(p=0.731$, unpaired $T$ test) or tibial-sided failure ( $p=0.61$, unpaired $T$ test). Alignment outliers $\left(>5^{\circ}\right.$ varus, reverse tibial slope, excessive PTS $>10^{\circ}$, femoral extension $>10^{\circ}$ or flexion of $>10^{\circ}$, and femoral valgus $>10^{\circ}$ or varus) were not associated with failure ( $p=0.534$, Chi-squared). Tibial ( $p=0.345$, Chi-squared) or femoral ( $p=0.299$, Chi-squared) malalignment was not significantly associated with failure. 
Table 4 Characteristics of intact and failed UKAs at 10 years

\begin{tabular}{|c|c|c|c|c|}
\hline & Intact $(n=92)$ & Failed $(n=17)$ & $p$ value & $95 \% \mathrm{CI}$ \\
\hline \multicolumn{5}{|l|}{ Demographics } \\
\hline Age & $69.3(9.1)$ & $63.9(6.6)$ & $0.019^{*}$ & \multirow[t]{2}{*}{-10.1 to -0.91} \\
\hline Female & $49[54]$ & $11[65]$ & $0.408^{\wedge}$ & \\
\hline BMI & $28.2(4.5)$ & $31.1(4.3)$ & $0.020^{*}$ & 0.45 to 5.20 \\
\hline Weight & $78.1(14.9)$ & $82.5(14.5)$ & $0.264^{*}$ & -3.42 to 12.35 \\
\hline \multicolumn{5}{|l|}{ GSR } \\
\hline Preop & $1.11(0.18)$ & $1.04(0.13)$ & $0.286^{*}$ & -0.2 to 0.06 \\
\hline 1 year & $1.03(0.2)$ & $1.15(0.21)$ & $0.077 *$ & -0.01 to 0.25 \\
\hline 5 years & $1.00(0.12)$ & $1.13(0.18)$ & $0.005^{*}$ & 0.04 to 0.20 \\
\hline \multicolumn{5}{|l|}{ GSR year 1 change } \\
\hline Absolute change & $-0.08(0.18)$ & $0.15(0.16)$ & $0.001 *$ & 0.10 to 0.36 \\
\hline$>10 \%$ increase & $6[10]$ & $6[67]$ & \multirow[t]{3}{*}{$<0.001^{\wedge}$} & \\
\hline$<10 \%$ change & $20[36]$ & $2[22]$ & & \\
\hline$>10 \%$ decrease & $29[53]$ & $1[11]$ & & \\
\hline \multicolumn{5}{|l|}{ Alignment } \\
\hline Femorotibial angle & $177.7(2.9)$ & $177.6(4.3)$ & $0.895^{*}$ & -2.3 to 1.5 \\
\hline Medial proximal tibial angle & $85.8(2.4)$ & $86.7(2.7)$ & $0.235^{*}$ & -1.1 to 2.2 \\
\hline Posterior tibial slope & $2.5(3.1)$ & $1.7(2.5)$ & $0.397 *$ & -1.6 to 1.2 \\
\hline Femur coronal (degrees of valgus) & $4.5(4.9)$ & $2.9(5.0)$ & $0.250^{*}$ & -1.1 to 4.9 \\
\hline Femoral flexion & $-1.0(7.0)$ & $-4.5(6.4)$ & $0.103^{*}$ & -7.7 to 0.7 \\
\hline \multicolumn{5}{|l|}{ PROMs } \\
\hline \multicolumn{5}{|l|}{ PCS } \\
\hline Preop & $31.5(7.0)$ & $26.9(7.7)$ & $0.212^{*}$ & -12 to 2.7 \\
\hline 1 year & $40.0(11.3)$ & $41.3(12.4)$ & $0.850^{*}$ & -12.6 to 15.2 \\
\hline 5 year & $40.9(11.2)$ & $37.4(14.4)$ & $0.520^{*}$ & -14 to 7.2 \\
\hline 10 year & $40.7(13.6)$ & $32.2(7.1)$ & $0.039^{*}$ & -16.7 to -0.4 \\
\hline \multicolumn{5}{|l|}{ MCS } \\
\hline Preop & $50.6(11.6)$ & $52.0(12.2)$ & $0.830 \mathrm{~T}$ & \\
\hline 1 year & $50.7(10.6)$ & $54.4(14.4)$ & $0.682 \mathrm{~T}$ & \\
\hline 5 year & $49.6(10.9)$ & $45.5(13.0)$ & $0.522 \mathrm{~T}$ & \\
\hline 10 year & $49.2(15.3)$ & $43.8(12.8)$ & $0.161 \mathrm{~T}$ & \\
\hline \multicolumn{5}{|l|}{ OKS } \\
\hline Preop & $20.3(6.0)$ & $18.3(4.9)$ & $0.698 \mathrm{~T}$ & \\
\hline 1 year & $33.9(9.4)$ & $29.3(11.1)$ & $0.525 \mathrm{~T}$ & \\
\hline 5 year & $36.1(10.1)$ & $26.4(13.7)$ & $0.104 \mathrm{~T}$ & \\
\hline 10 year & $34.1(10.9)$ & $26.6(8.4)$ & $0.014 \mathrm{~T}$ & \\
\hline
\end{tabular}

*Unpaired $T$ test, ${ }^{\wedge}$ Chi-squared, ${ }^{\mathrm{T}}$ Mann-Whitney $U$ test
Absolute GSR was significantly greater at 5 years in patients whose UKA went on to fail (Table 4) and implant survival was significantly worse in patients whose GSR had increased by $>10 \%$ (Fig. 3c; Tables 5, 6).

Sixteen UKAs in 12 patients underwent radioisotope bone scanning at mean $6.1 \pm 3.3$ years $(2.1-11.5$ years). Bone scanning was performed for reasons unrelated to the UKA in 4 cases. All UKAs that underwent radioisotope bone scanning showed well localised increased uptake in the medial proximal tibia under the tibial component. Seven went on to be revised: 4 for "unexplained" pain; 2 for tibial subsidence/loosening; and one for lateral OA. Of the 9 UKAs with hot bone scans who were not revised, 50\% were satisfied with their UKA at 5 years, but $100 \%$ were satisfied at 10 years. One reported medial pain at 5 years and one at 10 years.

In addition to the 17 failures already discussed, there were no other radiographic failures on review at a mean of $7.8 \pm 2.7$ years postoperatively. 
Table 5 Ten-year Kaplan-Meier survival analysis (end point=any cause failure) by subgroup

\begin{tabular}{llllll}
\hline Variable & Division & $N$ & Survival (\%) & $95 \%$ CI & $p$ value \\
\hline Gender & Male & 48 & 87.3 & $77.9-96.7$ & $0.501^{*}$ \\
& Female & 61 & 84.3 & $74.9-93.7$ & \\
Age & $<65$ years & 36 & 77.8 & $57.4-98.2$ & $0.035^{*}$ \\
& $\geq 65$ years & 73 & 89.7 & $82.4-97.0$ & \\
BMI & $\leq 30$ & 63 & 90.0 & $82.3-97.6$ & $0.017^{*}$ \\
& $>30$ & 31 & 71.0 & $54.9-87.1$ & \\
GSR & Increase by & 12 & 58.3 & $30.5-86.1$ & $<0.001^{*}$ \\
change & $>10 \%$ & & & & \\
in year 1 & Change < 10\% & 22 & 90.9 & $78.9-100$ & \\
& Decrease by & 30 & 96.6 & $89.9-100$ & \\
& $>10 \%$ & & & & \\
\hline
\end{tabular}

*Log-rank

\section{Discussion}

The 10-year survival of this UKA incorporating an all-polyethylene tibial component was found to be $85.5 \%$ (78.6-92.4 $95 \% \mathrm{CI}$ ) with failure for any reason as an end point. Unexplained pain was the commonest mode of failure $(6 / 17,35 \%)$ followed by osteoarthritis progression $(5 / 17,29 \%)$ and tibial subsidence/loosening $(4 / 17,24 \%)$. Survival was inferior in patients $<65$ years, in those with a BMI $>30$ and in those whose medial tibial bone density increased postoperatively. This was the case for all failures and for tibial-sided failures including pain. It is unclear whether age $<65$ or $\mathrm{BMI}>30$ is a more important risk factor for failure, but $44 \%$ (8/18) of patients who were both $<65$ years old and had a BMI $>30$ went on to fail. Revisions for unexplained pain were performed earlier than revisions for other reasons. In those with intact UKAs satisfaction at 10 years was high at $96 \%$ and improvements in OKS were maintained, despite slight deteriorations in pain levels as measured using VAS pain scores.

Our 10-year survivorship is consistent with UKA joint registry data $[1,2]$. Rates of aseptic loosening, progression of osteoarthritis and revision for unexplained pain are similar to those reported in the literature [10, 20]. Joint registries do not differentiate between all-polyethylene and metal-backed UKAs. In the literature there are reports of both favourable [6-9] and concerning survivorship of medial UKAs incorporating all-polyethylene tibial components [3-5]. The Norwegian Arthroplasty Register [21] reports significantly higher rates of revision at 5 years in 2 all-polyethylene designs compared to 3 metal-backed mobile bearing devices. Saenze et al. [3] report a failure rate of $11 \%(16 / 144)$ at mean 36 months with tibial failures in $12 / 16(75 \%)$. Mariani et al. [22] report a $38 \%$ revision rate $(15 / 39)$ at 12 months with femoral loosening in all failures. Hamilton et al. [23] reported 9/221 (4\%) revisions at 1-26 months, 4/9 for tibial loosening/collapse. These implants had minimum polyethylene (PE) thickness $7.5 \mathrm{~mm}$. In contrast, the St Georg Sled (Waldemar Link, Hamburg, Germany), an all-polyethylene implant with minimum polyethylene thickness $9 \mathrm{~mm}$ reports good long-term survival of 90-92\% at $10-15$ years $[6,7]$ with no revisions for ongoing pain and no early failures.

Concerns have thus been raised regarding the incidence of tibial loosening/subsidence in all-polyethylene tibial components [4, 24], and the role of implant stiffness in unexplained pain $[12,19,25]$. Such variable survival rates from $56 \%$ at 7 years (32-75 95\% CI) [4] to $87.6 \%$ at 10 years [9] in allpolyethylene designs suggest that not all all-polyethylene designs are equal, and this may reflect component thickness [13]. Components of $6 \mathrm{~mm}$ thickness have been significantly associated with early clinical failure [26], increased wear and osteolysis [27]. Pathological cancellous bone overload and tibial subsidence may affect thinner implants more so than thicker implants. Finite element analysis has shown that increasing all-polyethylene thickness to $10 \mathrm{~mm}$ still underperforms in terms of proximal tibial strain compared to metal-backed implants [13] with the added cost of increased tibial resection and associated reduction in cancellous bone strength [28].

Contrary to Cavaignac et al. [29] and Zengerink et al. [30] who reported no effect of obesity on revision rates in 212 and 147 patients, respectively, and consistent with a theory of bone overload and pain, we found significantly poorer survival in patients with $\mathrm{BMI}>30$. Increased risk of revision in patients under 65 years concurs with Dyrhovden et al. [31] who examined 725 revisions out of 7648 UKAs from the Norwegian Joint Registry. The combination of these two variables seemed particularly relevant here with $44 \%$ of those $<65$ years with a BMI $>30$ failing.

We have previously published a digital radiodensitometry technique in this UKA cohort to investigate the relative bone density of the medial proximal tibial [19]. A proxy measure of bone mineral density - the grey scale ratio (GSR) — was developed with a value of $>1.0$ reflecting relative medial sclerosis [19]. Consistent with other reports of BMD following UKA [32], we found that on average GSR decreases in the first year following medial UKA and then remains static. Increases in GSR were associated with worse OKS and pain. The present study confirms that an increase in relative sclerosis is also associated with worse 10-year survival. Similarly, Jacobs et al. [33] demonstrated that preoperative bone marrow oedema did not resolve following UKA, and that when present postoperatively was associated with worse pain. Both phenomena may reflect ongoing medial strain and adaptive remodelling. This is supported by persistently "hot" radioisotope bone scans here.

It has been previously suggested that proximal tibial adaptive remodelling after UKA stabilises at 2 years with resolution of pain at that stage [11]. This is not supported by 
Fig. 3 Kaplan-Meier analysis of 10-year survival with subgroup analysis for a age above and below 65 years, b BMI above and below 30 and $\mathbf{c}$ change in GSR over the first year
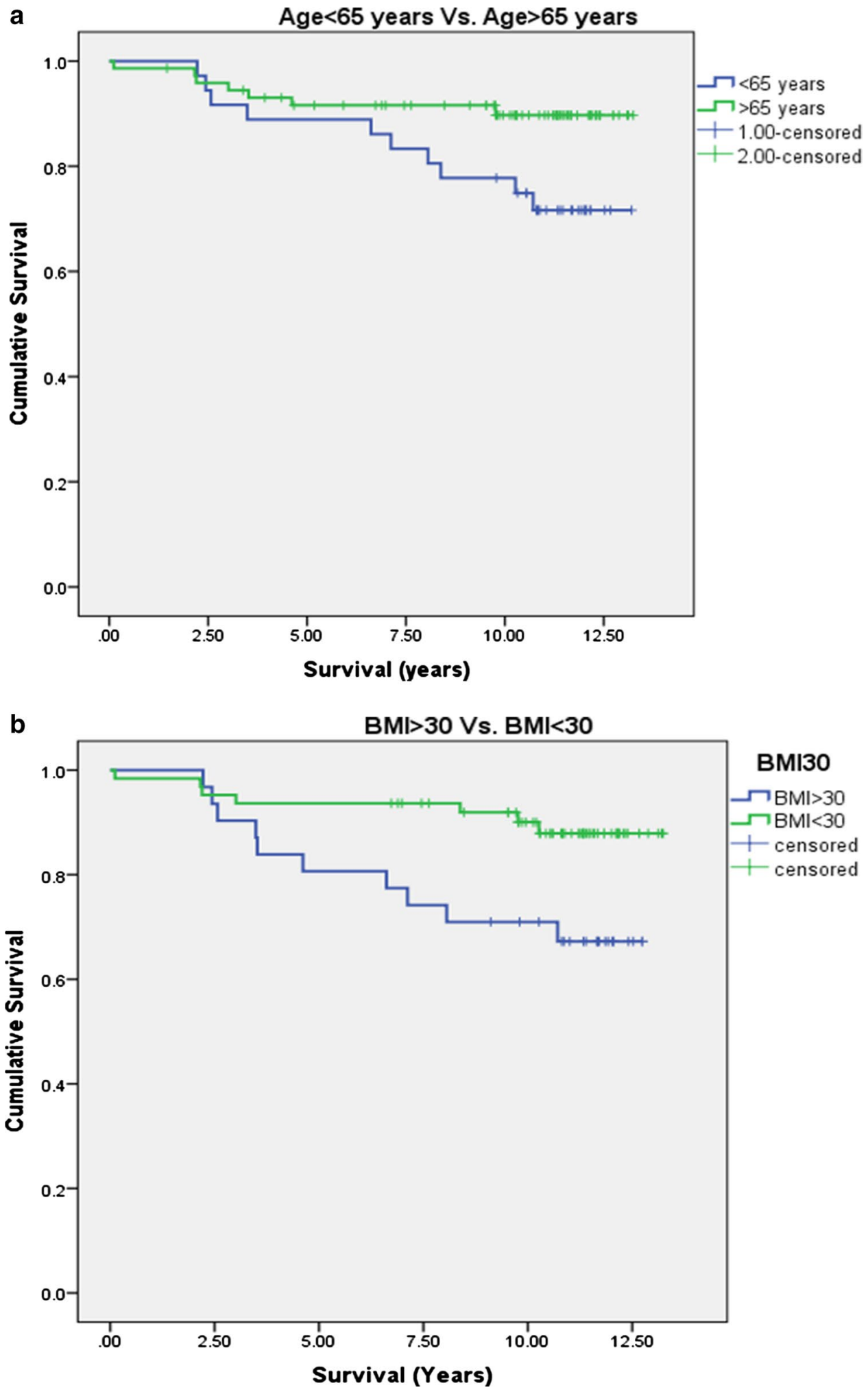

our results. When performed, bone scans demonstrated persistently high medial tibial uptake which did not resolve by 2 years and revisions for unexplained pain were performed up to 7 years, consistent with National Joint Registry data $[10,34]$. Thirty percent of patients reported ongoing medial pain at $>5$ years and $25 \%$ at 10 years. Persistently "hot" bone scans may reflect persistent bone marrow oedema and pain [33], but here not all those with "hot" bone scans reported ongoing pain. The role of bone scintigraphy in the investigation of painful UKAs remains unsupported [35]. 
Fig. 3 (continued)

C

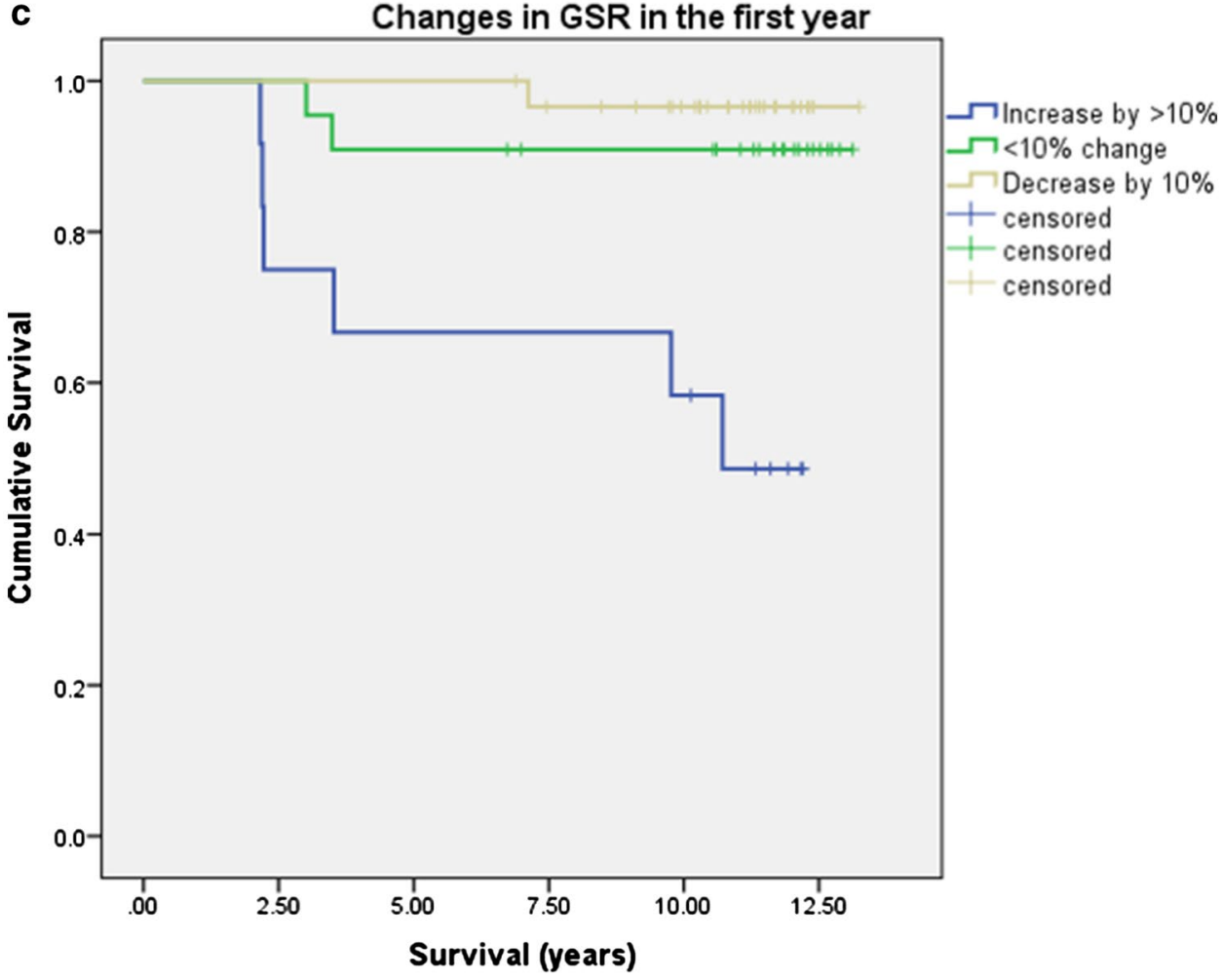

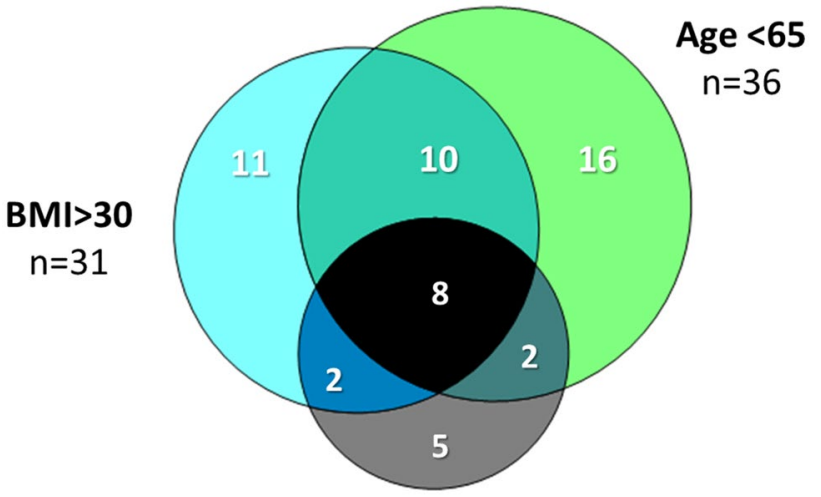

Failures

$n=17$

Fig. 4 Venn diagram showing the relationship between age $<65$, $\mathrm{BMI}>30$ and UKA failures

Revision to TKA for pain had a significantly worse OKS outcome compared to revisions for other reasons and this is consistent with Kerens et al. [36]. Though suboptimal implant alignment was not statistically predictive of failure, it may have played a role in up to $50 \%$ of failed UKAs.

Limitations of this study include the sample size and its retrospective nature. Implant alignment was measured on short-leg radiographs, not hip-knee-ankle radiographs,
Table 6 Ten-year Kaplan-Meier survival analysis (end point = tibialsided failures only) by subgroup

\begin{tabular}{|c|c|c|c|c|c|}
\hline Variable & Division & $N$ & Survival (\%) & $95 \% \mathrm{CI}$ & $p$ value \\
\hline \multirow[t]{2}{*}{ Gender } & Male & 48 & 87.3 & 77.9-96.7 & \multirow[t]{2}{*}{$0.458^{*}$} \\
\hline & Female & 61 & 92.5 & 85.4-99.6 & \\
\hline \multirow[t]{2}{*}{ Age } & $<65$ years & 36 & 83.2 & $71.0-95.4$ & \multirow[t]{2}{*}{$0.040 *$} \\
\hline & $\geq 65$ years & 73 & 93.8 & 87.9-99.7 & \\
\hline \multirow[t]{2}{*}{ BMI } & $\leq 30$ & 63 & 94.8 & $89.1-100$ & \multirow[t]{2}{*}{$0.004 *$} \\
\hline & $>30$ & 31 & 77.0 & $62.1-91.9$ & \\
\hline \multirow{3}{*}{$\begin{array}{l}\text { GSR } \\
\text { change } \\
\text { in year } 1\end{array}$} & $\begin{array}{l}\text { Increase by } \\
>10 \%\end{array}$ & 12 & 70.0 & $38.4-100$ & \multirow[t]{3}{*}{$0.001 *$} \\
\hline & Change $<10 \%$ & 22 & 90.9 & $78.9-100$ & \\
\hline & $\begin{array}{c}\text { Decrease by } \\
>10 \%\end{array}$ & 30 & 100 & & \\
\hline
\end{tabular}

*Log-rank

and may be less accurate. The Preservation UKA is no longer available and has since been redesigned as the Sigma Partial Knee (DePuy Synthes, Johnson \& Johnson, Raynham, Massachusetts, USA) with the addition of a peg to the keel of the tibia and an additional femoral component peg. The minimal thickness of all-polyethylene bearing has been increased to $8 \mathrm{~mm}$. No patients were lost to follow-up in this 10-year study the results of which highlight issues specific to all-polyethylene UKA components which should be considered in implant selection. 


\section{Conclusion}

This UKA incorporating an all-polyethylene tibial component was associated with a high rate of early failure between 2 and 5 years, predominantly due to unexplained pain and tibial-sided failure. Though metabolic changes in the medial proximal tibia appear to persist into the long term on bone scans, this is not necessarily symptomatic. The elevated rate of early revision did not persist with 10-year survival for all-cause failure of $85.5 \%$ (78.6-92.4 95\% CI). Patients $<65$ years of age and those with $\mathrm{BMI}>30 \mathrm{~kg} / \mathrm{m}^{2}$ displayed significantly worse 10 -year survival with this implant and $44 \%$ of patients with both risk factors went on to fail.

Acknowledgements The authors thank all of the orthopaedic surgeons whose patients were included in this study. The authors acknowledge the financial support of NHS Research Scotland (NRS), through Chloe Scott of NHS Lothian.

\section{Compliance with ethical standards}

Conflict of interest All authors declare that they have no conflict of interest.

Open Access This article is distributed under the terms of the Creative Commons Attribution 4.0 International License (http://creativeco mmons.org/licenses/by/4.0/), which permits unrestricted use, distribution, and reproduction in any medium, provided you give appropriate credit to the original author(s) and the source, provide a link to the Creative Commons license, and indicate if changes were made.

\section{References}

1. NJR (2014) NJR 11th Annual Report

2. Australian (2012) Australian Orthopaedic Association: National Joint Replacement Registry Hip and Knee Arthroplasty Annual Report 2012

3. Saenz CL, McGrath MS, Marker DR, Seyler TM, Mont MA, Bonutti PM (2010) Early failure of a unicompartmental knee arthroplasty design with an all-polyethylene tibial component. Knee 17(1):53

4. Hutt JR, Farhadnia P, Masse V, LaVigne M, Vendittoli PA (2015) A randomised trial of all-polyethylene and metal-backed tibial components in unicompartmental arthroplasty of the knee. Bone Joint J 97-B(6):786

5. Koh IJ, Suhl KH, Kim MW, Kim MS, Choi KY, In Y (2017) Use of all-polyethylene tibial components in unicompartmental knee arthroplasty increases the risk of early failure. J knee Surg 30(8):807

6. Newman J, Pydisetty RV, Ackroyd C (2009) Unicompartmental or total knee replacement: the 15-year results of a prospective randomised controlled trial. J Bone Joint Surg Br 91-B:52

7. Steele RG, Hutabarat S, Evans RL, Ackroyd CE, Newman JH (2006) Survivorship of the St Georg Sled medial unicompartmental knee replacement beyond 10 years. J Bone Joint Surg Br 88(9): 1164
8. Forster-Horvath C, Artz N, Hassaballa MA, Robinson JR, Porteous AJ, Murray JR, Newman JH (2016) Survivorship and clinical outcome of the minimally invasive Uniglide medial fixed bearing, all-polyethylene tibia, unicompartmental knee arthroplasty at a mean follow-up of 7.3 years. Knee 23(6):981

9. Bruni D, Gagliardi M, Akkawi I, Raspugli GF, Bignozzi S, Marko T, Bragonzoni L, Grassi A, Marcacci M (2016) Good survivorship of all-polyethylene tibial component UKA at longterm follow-up. Knee Surg Sports Traumatol Arthrosc Off J ESSKA 24(1):182

10. Baker PN, Petheram T, Avery PJ, Gregg PJ, Deehan DJ (2012) Revision for unexplained pain following unicompartmental and total knee replacement. J Bone Joint Surg Am 94(17):e126

11. Simpson DJ, Price AJ, Gulati A, Murray DW, Gill HS (2009) Elevated proximal tibial strains following unicompartmental knee replacement-a possible cause of pain. Med Eng Phys 31(7):752

12. Scott CE, Eaton MJ, Nutton RW, Wade FA, Pankaj P, Evans SL (2013) Proximal tibial strain in medial unicompartmental knee replacements: a biomechanical study of implant design. Bone Joint J 95-B(10): 1339

13. Scott CE, Eaton MJ, Nutton RW, Wade FA, Evans SL, Pankaj P (2017) Metal-backed versus all-polyethylene unicompartmental knee arthroplasty: proximal tibial strain in an experimentally validated finite element model. Bone Joint Res 6(1):22

14. Dunbar MJ, Robertsson O, Ryd L, Lidgren L (2001) Appropriate questionnaires for knee arthroplasty. Results of a survey of 3600 patients from the Swedish Knee Arthroplasty Register. JBJS Br 83(3):339

15. Dawson J, Fitzpatrick R, Murray D, Carr A (1998) Questionnaire on the perceptions of patients about total knee replacement. J Bone Joint Surg Br 80-B(1):63

16. Scott CEH, Howie CR, MacDonald D, Biant LC (2010) Predicting dissatisfaction following total knee replacement: a prospective study of 1217 patients. J Bone Joint Surg Br 92-B(9): 1253

17. Behrend H, Giesinger K, Giesinger JM, Kuster MS (2012) The "forgotten joint" as the ultimate goal in joint arthroplasty: validation of a new patient-reported outcome measure. J Arthroplast 27(3):430

18. Sarmah SS, Patel S, Hossain FS, Haddad FS (2012) The radiological assessment of total and unicompartmental knee replacements. J Bone Joint Surg Br 94-B(10):1321

19. Scott CEH, Wade FA, Bhattacharya R, MacDonald DJ, Pankaj $\mathrm{P}$, Nutton RW (2016) Changes in bone density in metal backed and all-polyethylene medial unicompartmental knee arthroplasty. J Arthroplast 31:702

20. van der List JP, Zuiderbaan HA, Pearle AD (2016) Why do medial unicompartmental knee arthroplasties fail today? J Arthroplast 31(5): 1016

21. Norwegian (2010) Annual report of the Norwegian arthroplasty register

22. Mariani EM, Bourne MH, Jackson RT, Jackson ST, Jones P (2007) Early failure of unicompartmental knee arthroplasty. J Arthroplast 22(6 Suppl 2):81

23. Hamilton WG, Collier MB, Tarabee E, McAuley JP, Engh CA Jr, Engh GA (2006) Incidence and reasons for reoperation after minimally invasive unicompartmental knee arthroplasty. J Arthroplast 21(6 Suppl 2):98

24. Bini S, Khatod M, Cafri G, Chen Y, Paxton EW (2013) Surgeon, implant, and patient variables may explain variability in early revision rates reported for unicompartmental arthroplasty. J Bone Joint Surg Am 95(24):2195

25. Small SR, Berend ME, Ritter MA, Buckley CA, Rogge RD (2011) Metal backing significantly decreases tibial strains in a medial unicompartmental knee arthroplasty model. J Arthroplast 26(5):777 
26. Heck DA, Marmor L, Gibson A, Rougraff BT (1993) Unicompartmental knee arthroplasty. A multicenter investigation with longterm follow-up evaluation. Clin Orthopaed Relat Res (286): 154

27. Hernigou P, Poignard A, Filippini P, Zilber S (2008) retrieved unicompartmental implants with full PE tibial component: the effects of knee alignment and polyethylene thickness on creep and wear. Open Orthopaed J 2:51

28. Hvid I (1988) Trabecular bone strength at the knee. Clin Orthopaed Relat Res 227:210

29. Cavaignac E, Lafontan V, Reina N, Pailhe R, Wargny M, Laffosse JM, Chiron P (2013) Obesity has no adverse effect on the outcome of unicompartmental knee replacement at a minimum follow-up of seven years. Bone Joint J 95-B(8):1064

30. Zengerink I, Duivenvoorden T, Niesten D, Verburg H, Bloem R, Mathijssen N (2015) Obesity does not influence the outcome after unicompartmental knee arthroplasty. Acta Orthopaed Belgica 81(4):776

31. Dyrhovden GS, Lygre SHL, Badawy M, Gothesen O, Furnes O (2017) Have the causes of revision for total and unicompartmental knee arthroplasties changed during the past two decades? Clin Orthopaed Relat Res 475(7):1874
32. Richmond BI, Hadlow SV, Lynskey TG, Walker CG, Munro JT (2013) Proximal tibial bone density is preserved after unicompartmental knee arthroplasty. Clin Orthopaed Relat Res

33. Jacobs CA, Christensen CP, Karthikeyan T (2016) Subchondral bone marrow edema had greater effect on postoperative pain after medial unicompartmental knee arthroplasty than total knee arthroplasty. J Arthroplast 31(2):491

34. Baker PN, Jameson SS, Deehan DJ, Gregg PJ, Porter M, Tucker K (2012) Mid-term equivalent survival of medial and lateral unicondylar knee replacement: an analysis of data from a National Joint Registry. J Bone Joint Surg Br 94(12):1641

35. Wong MY, Beadsmoore C, Toms A, Smith T, Donell S (2012) Does $99 \mathrm{mTc}-\mathrm{MDP}$ bone scintigraphy add to the investigation of patients with symptomatic unicompartmental knee replacement? Knee 19(5):592

36. Kerens B, Boonen B, Schotanus MG, Lacroix H, Emans PJ, Kort NP (2013) Revision from unicompartmental to total knee replacement: the clinical outcome depends on reason for revision. Bone Joint J 95-B(9):1204 